\title{
¿DE LA NO-GESTIÓN AL EMPRESARIALISMO? ALGUNAS EVIDENCIAS EN LA TRANSFORMACIÓN DE LA GOBERNANZA URBANA EN LAS CIUDADES MEDIAS LATINOAMERICANAS A TRAVÉS DE UN CASO DE ESTUDIO ECUATORIANO
}

\author{
José Prada-Trigo \\ Facultad de Ciencias de la Hospitalidad, Universidad de Cuenca (Ecuador) \\ y Universidad Politécnica Salesiana, Sede Cuenca (Ecuador) \\ pradatrigo@gmail.com
}

\section{RESUMEN}

El paso de la gestión al empresarialismo urbano es un tema importante en los estudios territoriales de los últimos años. Mientras que las urbes europeas y norteamericanas fueron pioneras en estos procesos y las metrópolis latinoamericanas adaptaron sus postulados a una realidad diferente, las ciudades intermedias de esta región parecen haber copiado los modelos de su entorno aplicándolos sin sentido crítico a un contexto caracterizado por carencias urbanas y sociales y bajos estándares de gobernanza urbana. El resultado ha sido una transición de la «no-gestión» al empresarialismo urbano, que se analiza e interpreta en este artículo a partir de un caso de estudio ecuatoriano.

Palabras clave: gestión, empresarialismo urbano, gobernanza, ciudades intermedias, Latinoamérica.

\section{ABSTRACT}

The transition from urban management to entrepreneurialism is an important issue in regional studies in recent years. While European and American cities were pioneers in

Fecha de recepción: enero 2015.

Fecha de aceptación: marzo 2015. 
these processes and the Latin American metropolises adapted their principles to a different reality, intermediate cities in this region seem to have copied the models of their environment uncritically applying them into a context by important urban and social deficiencies and low standards of urban governance. The result has been a transition from «non-managerialism» to urban entrepreneurialism, analyzed and interpreted in this article from a case study of Ecuador.

Keywords: managerialism, urban entrepreneurialism, governance, medium-sized cities, Latin America.

\section{INTRODUCCIÓN}

From managerialism to entrepreneurialism: The transformation in urban governance in late capitalism es uno de los textos más conocidos del geógrafo británico David Harvey. En él plantea cómo el gobierno de la ciudad ha pasado desde un modelo de gestión de corte gerencial y sustentado sobre la planificación integrada, hacia otro de gobernanza, basado en criterios empresariales (Harvey, 2001). Aunque el texto original fue escrito en 1989, la expansión por todo el planeta de esta transformación en la gobernanza urbana lo ha mantenido vigente. La progresiva difusión de estas ideas en la jerarquía urbana, desde las metrópolis hasta las ciudades pequeñas e intermedias ha dado pie a una amplia literatura que interpreta este proceso, mayormente con origen en los sistemas urbanos de Europa y Norteamérica, que acumulan más de treinta años de políticas de regeneración urbana (Korthals, 2002; Somoza, 2013). En ellas, se apuntan algunos problemas similares a los ya mencionados por David Harvey o Patsy Healey al hablar sobre la regeneración urbana en Baltimore o Glasgow (Harvey, 2001; Healey, et al., 1992): permanencia de viviendas de mala calidad, escasa atención a los problemas sociales, acelerada suburbanización y nuevas pautas sociales en torno al uso del automóvil y la proliferación de centros comerciales, como consecuencia de una falta de integración entre regeneración física y desarrollo social y económico (Carley, 2000).

Pese a que existen varios estudios sobre el proceso de regeneración urbana en metrópolis de América Latina como México D.F., Santiago de Chile, Bogotá o Buenos Aires, a partir del caso emblemático de Puerto Madero que ha dado pié a varios estudios sobre renovación urbana y gentrificación en esta ciudad (Kanai y Ortega-Alcázar, 2009; López-Morales, 2010; Cuenya y Corral, 2011), aún se da una carencia de estudios sobre ciudades de tamaño intermedio latinoamericanas y regeneración urbana, contándose apenas con algunas reflexiones que abordan muy tangencialmente la renovación urbana dentro de otras cuestiones como la renovación de las calles comerciales (Tella y Potocko, 2013) o la reducción de las desigualdades en el interior de las ciudades de la región (ONU Hábitat, 2014).

En general, los estudios sobre regeneración urbana en las grandes ciudades latinoamericanas ponen de manifiesto la existencia de una gestión de tipo empresarialista en estas actuaciones que sigue los parámetros de las intervenciones europeas, es decir, el cambio desde las estrategias orientadas al ordenamiento territorial, la obra pública y la prestación de servicios de bienestar social a la ciudadanía, hacia otras cuyo fin es el crecimiento económico, la asunción de riesgos, la innovación y una orientación al sector privado (Rodríguez, Moulaert 
y Swyngedow, 2001; Cuenya y Corral, 2011). De esta forma, las estrategias de renovación en América Latina parecen haber copiado el lenguaje y los modelos de gestión utilizados en las intervenciones europeas o norteamericanas adaptándolos a su realidad socioterritorial (López-Morales, 2010: 163; Williams, 2014; Kanai y Ortega-Alcázar, 2009: 484). Sin embargo, no existen estudios que analicen lo sucedido en las ciudades de tamaño intermedio latinoamericanas, que junto con problemas comunes a los de sus metrópolis (barrios desfavorecidos, ausencia de servicios básicos, infraestructuras deficientes) presentan unos estándares de participación social y gestión territorial mínimos, al propiciar estos ambientes, en general menos complejos, la aparición de estructuras sociales muy conservadoras, cerradas y basadas en redes de influencia hacia el poder político (Vilagrasa, 1999).

Por esto, la transformación de la gobernanza urbana en las ciudades intermedias latinoamericanas parece un tema relevante en la medida en que los estándares preexistentes (ausencia de gestión, gobiernos ineficientes) podrían haber dado paso a un empresarialismo urbano que, tomando como modelo las intervenciones en grandes ciudades de sus entornos, les permiten aproximarse a las formas de gobierno y crecimiento urbano globales. De esta forma, existiría una transición «de la no-gestión» al empresarialismo urbano sin que se haya dado una adopción de medidas de gestión y planificación, lo que puede provocar ineficiencias en la superación de las desigualdades sociales o de los problemas urbanos más acuciantes (servicios, vivienda, áreas verdes, etc.).

Para llevar a cabo este trabajo de investigación, a través del caso de estudio de Machala, Ecuador, se utilizaron distintos enfoques en las diferentes fases del mismo. Primeramente, se recurrió a una revisión de bibliografía internacional, con especial hincapié en la literatura latinoamericana, que permitiese la construcción de un marco teórico solvente. A continuación, se utilizaron fuentes y datos estadísticos, provenientes principalmente del Instituto Nacional de Estadística y Censo de Ecuador (INEC) y de ONU Hábitat, de tal forma que se pudieran comparar distintos aspectos vinculados a la evolución urbana. Con la intención de triangular datos de diferente naturaleza, y aportar así una mayor fiabilidad a la investigación (Yeung, 2003), se llevó a cabo una doble tarea de recopilación bibliográfica y desarrollo de la entrevista en profundidad. Por un lado, se rastrearon las obras académicas existentes que hacían referencia a los procesos de urbanización en Machala y Guayaquil. Dado que la mayoría de trabajos se centraban en la recuperación de esta última ciudad, y los estudios sobre Machala resultaron difíciles de localizar, se utilizaron a algunas obras dispersas que permitiesen apreciar las similitudes entre ambos casos. Con la intención de reforzar estas lagunas de información, se recurrió a la entrevista en profundidad a actores locales, una metodología que puede aportar mucho a la investigación geográfica en combinación con otras fuentes (DeLyser y Sui, 2014: 295). De esta forma, se elaboró una muestra de actores locales y supralocales, pertenecientes a los ámbitos de la política, la economía y la sociedad de la provincia de El Oro (tabla 1) que constituyó la fuente principal de información, e hizo posible interpretar las claves de los procesos analizados a través del trabajo de campo, por lo que es necesario agradecer su colaboración. Con la finalidad de favorecer la expresión de las opiniones con mayor libertad, se decidió recurrir al anonimato en el momento de transcribir alguna parte de las entrevistas en el artículo. Por último, se recorrieron los espacios regenerados en ambas ciudades, tomándose fotografías que permitieran ilustrar algunos aspectos destacados en el texto. 
Tabla 1

RELACIÓN DE ACTORES ENTREVISTADOS E INSTITUCIÓN A LA QUE PERTENECEN

\begin{tabular}{|l|l|}
\hline ACTOR & INSTITUCIÓN (cargo) \\
\hline Arq. Juan Cisneros Echeverría & Dpto. Urbanismo Municipalidad de Machala (Dir.) \\
\hline Arq. Iván Cruz & Experto Local (Varias instituciones) \\
\hline Arq. Oswaldo Pizarro & Colegio de Arquitectos de El Oro (Pte.) \\
\hline Arq. Jesús Espinosa & Universidad Técnica de Machala (Prof.) \\
\hline Dr. Óscar Serrano & Universidad Técnica de Machala (Prof.) \\
\hline Ing. Teresa Rodas & Corporación Orense de Desarrollo Territorial (Pte.) \\
\hline Lic. Ramón Mora & Revista Primera Plana (Dir.) \\
\hline Ing. Carlos Rodríguez & Diario Opinión (Redactor Jefe) \\
\hline
\end{tabular}

Fuente: Elaboración propia.

\section{LA PROBLEMÁTICA DE LA GESTIÓN URBANA Y LA PARTICIPACIÓN SOCIAL EN LATINO- AMÉRICA}

En su texto clásico, From managerialism to entrepreneurialism: The transformation in urban governance in late capitalism, David Harvey plantea de manera magistral el modo en que la ciudad ha pasado desde un modelo de gestión, de corte gerencial y sustentado sobre la intervención y organización de las ciudades y la solución de los problemas y diferencias sociales, hacia otro de gobernanza, basado en crecientes criterios empresariales para su gobierno (EURE, 2009). De esta forma, la crisis del modelo fordista en la década de los setenta, con la desindustrialización, crecimiento del desempleo estructural, austeridad fiscal, auge del neoconservadurismo, privatizaciones, etc. supone un giro en el gobierno de las ciudades, con un énfasis mayor en el papel de los gobiernos locales para atajar esos males y aproximarse a los flujos internacionales de capital (Harvey, 2001: 348). Se desarrolla desde ese momento un enfoque empresarialista, cuya prioridad deja de ser la redistribución equitativa de los recursos y la búsqueda de un desarrollo armónico, para pasar a ser el crecimiento y la reestructuración competitiva su principal objetivo, con intervenciones puntuales en determinadas áreas de la ciudad, que buscan maximizar los rendimientos de capital y la inversión externa (De Mattos, 2010: 156).

En América Latina, la gestión territorial ha estado tradicionalmente influenciada por visiones provenientes de otros lugares, lo que ha llevado a la aplicación de medidas a veces descontextualizadas de su realidad territorial (Fernández-Satto y Vigil-Greco, 2007). Esto sucedió, por ejemplo, en el caso de las políticas de gestión y planificación territorial, desarrolladas en el contexto europeo y norteamericano, y difundidas en América Latina desde los años sesenta, preconizadas por la Comisión Económica para América Latina (CEPAL) y el Instituto Latinoamericano de Planificación Económica y Social (ILPES). En ese momento se dio la necesidad de una planificación comprensiva y centralizada, al servicio de un modelo de desarrollo económico y social de fuerte inspiración keynesiana y con un intenso intervencionismo del Estado, a través de un crecimiento «hacia adentro» (con los mercados internos 
como soportes principales de la industria nacional), de una industrialización sustitutiva de importaciones y de un creciente intervencionismo estatal, con el objetivo de que estos estados abandonasen la situación de subdesarrollo y emprendiesen el camino de superación de la pobreza (De Mattos, 2010).

Sin embargo, los escasos resultados del modelo de planificación y su incapacidad para mejorar sustancialmente las condiciones de vida de la población, junto a la comentada crisis del modelo de acumulación fordista en la década de los setenta y un contexto regional marcado por la fragilidad fiscal y problemas en las balanzas de pagos, llevaron al abandono de este tipo de prácticas y a su reemplazo por un discurso diametralmente contrario. Como consecuencia de la brutal deuda de los países latinoamericanos y de las presiones externas, se consolidó un nuevo modelo, en el cual el Estado debía retirarse para no obstaculizar el funcionamiento de los mercados. En el contexto latinoamericano, dicho cambio se tradujo en un abandono de los supuestos de la CEPAL y en la aplicación de unos planes de ajuste económico, de privatización y de reducción del Estado, amparados en lo que se ha conocido como el «Consenso de Washington». En el mismo, se planteó la liberalización financiera, se impuso la privatización y el cierre de empresas estatales, junto a profundas reformas fiscales y del mercado de trabajo, en aras de la estabilidad macroeconómica, el control de la inflación y el crecimiento de la economía a largo plazo, integrando los preceptos básicos del empresarialismo urbano (Saad-Filho, 2005).

La reforma del Estado propuesta por esta estrategia contempla la reducción de la participación pública y su papel complementario en la economía, dejando libre el camino a la entrada de otros actores del sector privado. De esta forma, las nuevas estrategias de crecimiento económico pasan a depender en mayor medida de la escala local y de la capacidad que tienen las ciudades para movilizar su capital humano y económico para llevar a cabo y atraer inversiones y poner en marcha proyectos de desarrollo que impulsen a unos espacios sobre otros y lleven a una diferenciación de determinadas ciudades, capaces de posicionarse ventajosamente en el nuevo escenario global.

Es en este contexto en el que se da la paulatina aparición y consolidación de la gobernanza en el contexto latinoamericano en un proceso de retroalimentación entre la participación social o comunitaria (a través de ONGs, asociaciones, etc.) y la participación política (mediante procesos electorales y consultas, elección de candidatos, manifestaciones, etc.) que consolidarían la idea regional de gobernanza (Gaventa y Valderrama, 1999). Sin embargo, en el caso de América Latina, se encuentran dos elementos paralelos que aportan singularidad a este nuevo modelo de gestión territorial. Por un lado, una baja tradición en ámbitos como la participación social, que se traduce en un limitado desarrollo de organizaciones sociales y en que a menudo éstas no se encuentren institucionalizadas (Scarlato, 2013) ocupando el Estado un rol central, lo que conlleva un menor nivel de participación política que en otras regiones del planeta (Nickson, 2011). Por otro lado, la trayectoria de América Latina, marcada por altas tasas de desigualdad social, inseguridad y violencia o pobreza, hace que algunos autores hayan considerado la idea de gobernanza desde una perspectiva vinculada al propio funcionamiento democrático del Estado y a la aplicación de políticas eficaces desde arriba hacia abajo que resulten efectivas ante dichos retos (Mainwaring y Scully, 2008). Por ello, parece importante la recuperación del papel regulador del Estado después de varias décadas en las que la descentralización política, el adelgazamiento del Estado central y la difusión 
generalizada de la corrupción habían impedido esto. Como señala Boisier, el proceso de descentralización política en América Latina requiere en paralelo de la existencia de un Estado fuerte capaz de imponer unas directrices territoriales homogéneas y de colaborar con las instituciones locales (Boisier, 2006).

En el caso de Ecuador, la cuestión de la consolidación de la sociedad civil aparece marginal y tardíamente, incluso en el contexto latinoamericano, en parte debido a su escasa participación en la reinstauración de la democracia en el país, que le restó visibilidad en el conjunto del espectro sociopolítico ecuatoriano (Ramírez, 2009). De esta forma, no será hasta la segunda mitad de los años ochenta, en el marco del progresivo apuntalamiento del estado neoliberal, cuando la sociedad civil comience a emerger, en torno a la demanda de lógicas de acción pública no centradas en el mercado y a la reivindicación de derechos ciudadanos, en un momento en el que el Estado ha perdido gran parte de sus capacidades reguladoras y redistributivas y los gobiernos populistas arrecian en el poder central y en buena parte de las ciudades del país (Keese y Freire, 2006). En ese momento, cuando en otros países latinoamericanos se inicia una fase de redemocratización traducida en una nueva forma de proximidad entre la política y la ciudad que supera aquella tradicional relación construida por los partidos a partir del clientelismo y la ausencia de políticas sobre la ciudad, en Ecuador se mantiene un déficit de representación (Carrión, 1996). Así, en buena parte de la región el municipio consolida un modelo empresarial -semejante al que señala David Harvey- que define al Alcalde como Gerente y que busca la eficiencia a partir de la administración de los servicios y el desarrollo del mercado como salida del caos, sustentada en un modelo privatizador (Carrión, 1998: 79). Sin embargo, en Ecuador las décadas de los ochenta y noventa suponen la aparición de gobiernos locales no representativos, que no tienen una política urbana explícita, ni mecanismos de participación de la población, generando crecientes problemas de gobierno en esas propias ciudades, con lo que se da una crisis de gobernabilidad por la falta de representación, de participación, de políticas y por la imposibilidad de construir un proyecto colectivo de ciudad (Carrión, 1996: 18-20). Por ello, habrá que esperar hasta los albores del siglo XX para ver la aparición de los modelos de gestión empresarial en el país. A continuación, se analizan e interpretan estos elementos en base al caso de estudio de la ciudad de Machala.

\section{EL DESARROLLO URBANO DE MACHALA Y EL «MODELO GUAYAQUIL»}

Machala es una ciudad que en 2010 tenía una población de 249.000 habitantes, lo que la convierte en la sexta más poblada del país, ubicada al suroeste de Ecuador (figura 1) junto a la costa. Machala es capital de la provincia de El Oro, que con algo más de 600.000 habitantes acoge al 4,15\% de la población de Ecuador, siendo la sexta provincia más poblada del país. A pesar de su ubicación fronteriza con Perú y de la riqueza natural de la zona, este territorio tuvo un escaso poblamiento hasta mediados del siglo XX, momento en que se consolida una economía agroexportadora que implicó un intenso crecimiento en toda la provincia y, especialmente, en su capital.

El desarrollo urbano de Machala durante la etapa colonial fue, por lo tanto, muy débil, estando la ciudad constituida por aquel entonces por unas pocas casas y haciendas, y existiendo ya una dependencia económica, cultural, política e ideológica de Guayaquil (Murillo, 
2009: 11). A comienzos del siglo XX, como consecuencia de la adquisición de la capitalidad provincial y del auge cacaotero que vive Ecuador, la población de Machala pasa por un primer momento de crecimiento, alcanzando los 5.000 habitantes y desarrollando algunos servicios como alumbrado público o ferrocarril gracias a los impuestos recibidos por el cacao (Narváez y Vinuesa, 2003). De esta forma, la ciudad llega a la mitad del siglo con un aspecto cuidado, semejante en sus edificaciones a Guayaquil, y una población de 7.549 habitantes en 1950. Esta situación se verá completamente modificada con el auge del sector bananero a partir de la década de los 50. Como consecuencia de la demanda de abundante mano de obra para trabajar en el cultivo del banano se produce una llegada masiva de población desde el interior de Ecuador, que lleva al crecimiento de una serie de ciudades medias en la costa y alrededores: Machala, Portoviejo, Santo Domingo o Babahoyo, entre otras.

A esta situación ayuda una labor del Estado promocionando el cultivo de banano mediante subvenciones e invirtiendo en infraestructuras viales y portuarias que permitieran la salida de la mercancía hacia los mercados exteriores (Robert, 2009). El resultado es una acelerada transformación social en la que los terratenientes se convierten en empresarios y los agricultores tradicionales devienen obreros agrícolas (Barrantía, 1991). La ciudad refuerza su papel como centro comercial y de servicios, integrándose en el sistema capitalista como un espacio exportador de bienes primarios sin ningún valor agregado.

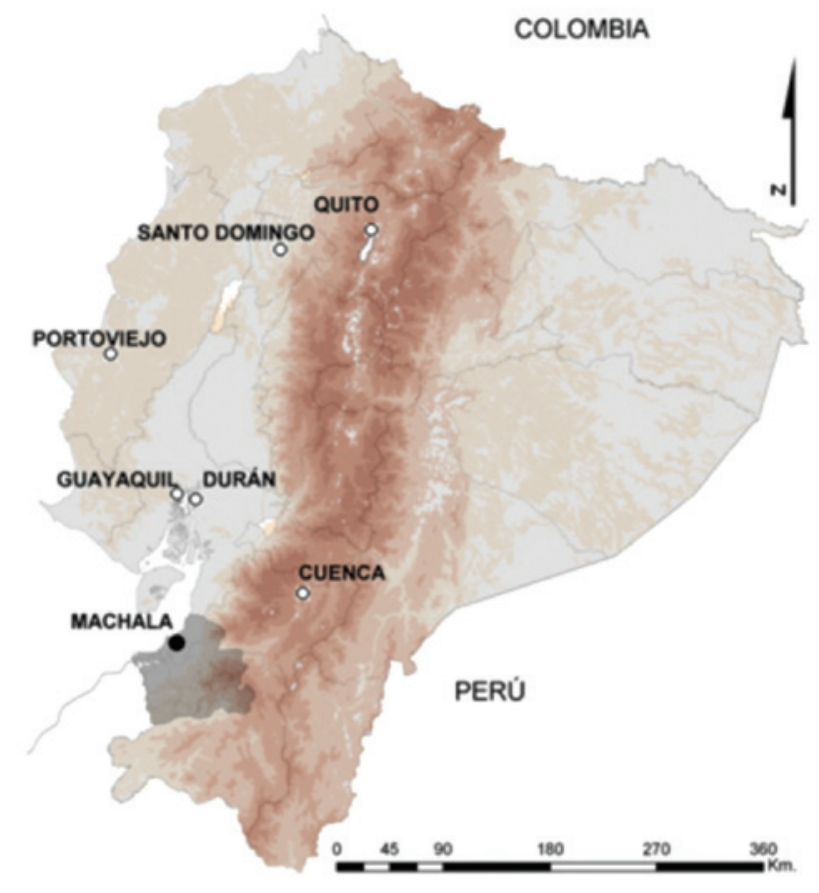

Fuente: Elaboración propia. 
El incremento de la población implica un crecimiento acelerado y desordenado de la ciudad: se producen invasiones de terrenos, alzándose barriadas de casas bajas, con materiales ínfimos y donde no llegan los servicios ni existen las condiciones mínimas de salubridad, en general sobre áreas inundables. También aparece un sector comercial informal, que provee de bienes de consumo a bajo precio a los trabajadores agrícolas y que termina de modificar el modelo económico imperante hasta entonces en Machala (Portais y León, 1987). Este crecimiento acelerado, junto con el progresivo deterioro de la situación política que vive el país (con dictaduras militares seguidas de gobiernos populistas y agitación social) afectarán a la manera de gestionar la ciudad. Desde la década de los setenta se produce un paulatino abandono de cualquier preocupación por la ordenación o la planificación urbana, arrecia la corrupción y se desatienden las necesidades mínimas en cuanto a equipamientos áreas verdes, asfaltado o prevención de inundaciones, todo ello en unos años en los que Machala se había convertido en la cuarta ciudad más poblada de Ecuador y en la de mayor crecimiento demográfico, con una creciente inseguridad ciudadana y una destrucción acelerada del paisaje urbano y natural (Murillo, 2009: 61-65).

En este contexto, el año 2005 llega a la alcaldía de la ciudad Carlos Falquez Batallas, del partido socialcristiano (PSC), de tendencia de derecha, tras ganar al entonces alcalde Mario Minuche, del populista Partido Roldosista Ecuatoriano (PRE), quien había gobernando la ciudad durante 12 años. Se abre desde ahora un nuevo período político caracterizado por la aplicación a pequeña escala de las mismas medidas desarrolladas en Guayaquil una década antes por León Febres Cordero y Jaime Nebot, compañeros de partido de Falquez.

Guayaquil se encontraba en la década de los noventa del siglo XX en una situación similar a la de Machala: grandes barriadas provenientes de invasiones, falta de servicios y espacios verdes, desorden urbanístico, ausencia de gestión, inseguridad, escasa autoestima de los ciudadanos, etc. En 1992, con la llegada de Febres Cordero a la alcaldía se inicia un período de reformas encaminado a la implementación de medidas de corte empresarialista: reducción de los trabajadores de la municipalidad, privatización de varios servicios públicos como recogida de basuras, abastecimiento de agua y alcantarillado, o la creación de varias fundaciones para gestionar la ciudad (Chiriboga, 2007). En 1996 comienza la recuperación del malecón de Guayaquil como obra emblemática de la alcaldía y elemento catalizador de dos procesos, la mejora de la autoestima ciudadana, y la atracción de inversión privada a la ciudad como herramienta para la regeneración de ésta (Wong, 2005: 183), siguiendo un modelo de gestión empresarialista de la ciudad. La renovación del Malecón 2000 (como se bautiza a esta obra) supone una verdadera «aniquilación» del espacio público y de la identidad patrimonial de la ciudad, que es derribada en beneficio de una arquitectura de carácter genérico, articulada alrededor de una serie de centros comerciales, y con un bajo interés por las cuestiones medioambientales. El objetivo es crear una tipología de ciudad con características similares al que promueve el urbanismo de EEUU, con los casos de Miami y Los Ángeles como modelo (Andrade, 2007: 117-118).

Este proceso será continuado por Jaime Nebot, que sustituye desde 2000 a León Febres Cordero, mediante la culminación del Malecón 2000, la renovación del cerro de Santa Ana y de otros enclaves de la clase media guayaquileña. En todos estos espacios se produce una concesión a fundaciones en el caso de que exista necesidad de gestionar y la seguridad se delega a empresas privadas, dándose un fenómeno de «limpieza social» que elimina de los 
lugares renovados a clases populares, prostitutas, mendigos, homosexuales y elementos no acordes con la ideología establecida (Garcés, 2004).El resultado ha sido la configuración de una ciudad aséptica, gestionada desde una óptica tecno-liberal (Allán, 2011: 76) y orientada a la segregación social y la atracción del turismo y las inversiones (el Malecón se ha llenado de franquicias y sus alrededores de hoteles de categoría media-alta). Mientras tanto, los problemas sociales de Guayaquil persisten, en una ciudad que en diciembre de 2013 presentaba el porcentaje de pobreza más elevado de las grandes ciudades ecuatorianas: un 16,66\% de su población era pobre frente al 6,08\% de Quito o el 4,99\% de Cuenca (INEC, 2014).

En el caso de Machala, puede encontrarse una respuesta similar a la de Guayaquil frente a estos retos que, como vimos, son muy semejantes a los de la metrópolis costeña, y unas consecuencias similares, dado que, por ejemplo, el porcentaje de pobreza en Machala era para ese período del 12,26\%, muy similar al de Guayaquil (INEC, 2014).Otro indicador relevante, la evolución del índice de Gini, nos muestra cómo en Machala éste ha tenido una dinámica sensiblemente peor que el promedio de las ciudades de tamaño medio ecuatorianas para las que existe dicho índice, habiéndose mantenido estable entre 2005 y 2010, período en el que tanto en este conjunto de ciudades, como en el total del espacio urbano y en el país dicho indicador mostró descensos más o menos acusados (tabla 2). De hecho, los datos de ONU Hábitat (2014: 213) muestran que en Machala, ciudad para la que existe un registro de datos desde 1999, este índice se mantiene estable desde 2002 en 0,477 tras haber empeorado su registro de 1999, 0,413, lo que demuestra tanto la incapacidad del modelo de gestión anterior como la del actual para revertir los problemas de desigualdad social.

Si se acude a los datos de evolución del empleo y el subempleo, que proporciona el INEC (2014b), puede observarse la evolución de otros indicadores sociales. En primer lugar, la tasa de desempleo (tabla 3) muestra como Machala, pese a un importante descenso en el último año, continúa mostrando una tasa de desempleo elevada, junto a Guayaquil, que se sitúa en cabeza de las ciudades ecuatorianas para las que existe dicho dato. Otro indicador relevante es la tasa de subempleo (tabla 4) que refleja las personas con empleo pero dispuestas a modificar su situación laboral para incrementar la duración o la productividad de su trabajo, es decir, aquellas ramas de actividad que, por el número de horas laborables o por el carácter poco intensivo de su trabajo (venta ambulante o prestación de servicios en la calle principalmente), constituyen los sectores más vulnerables de la ciudad. Como puede observarse, hasta diciembre de 2012 Machala encabezaba el porcentaje de empleo en esta categoría, a varios puntos de ciudades como Quito y Cuenca. Aunque en el último año este indicador ha aumentado, el mayor incremento en Guayaquil y Ambato ha significado una mejora de su posición relativa. Sin embargo, la lectura de estos indicadores socioeconómicos debe realizarse conjuntamente con la evolución de la gestión de la ciudad, para obtener así una imagen más completa de las dinámicas que se desarrollan en Machala en la última década. Por ello, a continuación, se interpreta hasta qué punto el modelo de gestión de la ciudad de Machala y el urbanismo diseñado por sus gobernantes ha seguido el ejemplo de Guayaquil y han dado lugar a procesos sociales y económicos más o menos integradores o excluyentes. Esto se realiza, como se dijo antes, principalmente en base al trabajo de campo y la entrevista a actores locales vinculados al desarrollo urbano y territorial de Machala. 
Tabla 2

EVOLUCIÓN DEL ÍNDICE DE GINI EN LAS CIUDADES DE TAMAÑO INTERMEDIO DE ECUADOR (2005-2010)

\begin{tabular}{|l|r|r|r|}
\hline Cantón & $\mathbf{2 0 0 5}$ & $\mathbf{2 0 1 0}$ & Dif. 2005-2010 \\
\hline Babahoyo & 0,455 & 0,589 & 0,13 \\
\hline Tulcán & 0,457 & 0,517 & 0,06 \\
\hline Azogues & 0,514 & 0,553 & 0,04 \\
\hline Vuelta Larga & 0,455 & 0,492 & 0,04 \\
\hline Durán & 0,435 & 0,460 & 0,03 \\
\hline Machala & $\mathbf{0 , 4 4 7}$ & $\mathbf{0 , 4 4 7}$ & $\mathbf{0 , 0 0}$ \\
\hline Riobamba & 0,475 & 0,470 & $-0,01$ \\
\hline Nueva Loja & 0,460 & 0,450 & $-0,01$ \\
\hline Manta & 0,442 & 0,430 & $-0,01$ \\
\hline Promedio ciudades intermedias & 0,470 & 0,455 & $-0,01$ \\
\hline Loja & 0,448 & 0,431 & $-0,02$ \\
\hline Guaranda & 0,483 & 0,459 & $-0,02$ \\
\hline La Troncal & 0,431 & 0,397 & $-0,03$ \\
\hline Esmeraldas & 0,554 & 0,517 & $-0,04$ \\
\hline Ibarra & 0,479 & 0,435 & $-0,04$ \\
\hline Portoviejo & 0,503 & 0,453 & $-0,05$ \\
\hline Ambato & 0,495 & 0,440 & $-0,06$ \\
\hline Cuenca & 0,447 & 0,388 & $-0,06$ \\
\hline Latacunga & 0,522 & 0,451 & $-0,07$ \\
\hline La Maná & 0,453 & 0,371 & $-0,08$ \\
\hline Quevedo & 0,449 & 0,356 & $-0,09$ \\
\hline Total áreas urbanas Ecuador & $\mathbf{0 , 5 1 3}$ & $\mathbf{0 , 4 8 5}$ & $\mathbf{- 0 , 0 3}$ \\
\hline Total Ecuador & $\mathbf{0 , 5 3 1}$ & $\mathbf{0 , 4 9 6}$ & $\mathbf{- 0 , 0 4}$ \\
\hline
\end{tabular}

Fuente: ONU Hábitat (2014).

Tabla 3

EVOLUCIÓN DE LA TASA DE DESEMPLEO EN LAS CIUDADES DE ECUADOR (2011-2013)

\begin{tabular}{|l|c|c|c|}
\hline & Diciembre 2011 & Diciembre 2012 & Diciembre 2013 \\
\hline Quito & $4,33 \%$ & $4,44 \%$ & $4,04 \%$ \\
\hline Guayaquil & $5,93 \%$ & $5,54 \%$ & $5,74 \%$ \\
\hline Cuenca & $3,91 \%$ & $3,69 \%$ & $3,68 \%$ \\
\hline Machala & $\mathbf{4 , 5 9 \%}$ & $\mathbf{4 , 4 0 \%}$ & $\mathbf{3 , 8 3 \%}$ \\
\hline Ambato & $2,33 \%$ & $3,35 \%$ & $3,39 \%$ \\
\hline Ecuador & $4,21 \%$ & $4,12 \%$ & $4,15 \%$ \\
\hline
\end{tabular}

Fuente: Elaboración propia a partir de datos de INEC (2014b). 
Tabla 4

EVOLUCIÓN DE LA TASA DE SUBEMPLEO EN LAS CIUDADES DE ECUADOR (2011-2013)

\begin{tabular}{|l|c|c|c|c|}
\hline & Diciembre 2011 & Diciembre 2012 & Diciembre 2013 & Diferencia 2011-2013 \\
\hline Quito & $35,32 \%$ & $26,29 \%$ & $29,93 \%$ & $-5,38 \%$ \\
\hline Guayaquil & $39,53 \%$ & $34,21 \%$ & $41,11 \%$ & $1,58 \%$ \\
\hline Cuenca & $33,77 \%$ & $30,69 \%$ & $31,68 \%$ & $-2,09 \%$ \\
\hline Machala & $\mathbf{4 1 , 4 5 \%}$ & $\mathbf{3 8 , 4 5 \%}$ & $\mathbf{4 0 , 2 5 \%}$ & $\mathbf{- 1 , 2 0 \%}$ \\
\hline Ambato & $40,28 \%$ & $37,89 \%$ & $48,54 \%$ & $8,26 \%$ \\
\hline Nacional urbano & $44,04 \%$ & $39,62 \%$ & $43,18 \%$ & $-0,86 \%$ \\
\hline
\end{tabular}

Fuente: Elaboración propia a partir de datos de INEC (2014b).

\section{INTERPRETACIÓN DEL PROCESO DE REGENERACIÓN URBANA EN MACHALA}

Tras este desarrollo del estado de la cuestión y la introducción a la evolución urbanística de Machala, con una breve referencia al modelo seguido por la ciudad de Guayaquil, a continuación se realiza una interpretación del modelo de gestión urbana de Machala a partir del trabajo de campo y las entrevistas mencionadas previamente. Éstas deben servir para consolidar o cuestionar las tendencias que ya han apuntado la recopilación bibliográfica y las estadísticas disponibles a nivel local: la sustitución de un modelo populista y corrupto, amparado en los clientelismos políticos, por otro de empresarialismo urbano. En dicho modelo, la regeneración urbana habría sido la principal herramienta para la consolidación de un proyecto político de la derecha, y de los grupos de poder oligárquicos afines a ésta, como ha sucedido en Guayaquil, a partir de una copia de las intervenciones llevadas a cabo en esta ciudad. Sin embargo, dicho modelo no ha prestado solución a los problemas de fondo existentes en Machala, habiendo puesto un mayor interés en generar un ambiente más atractivo para las inversiones comerciales e inmobiliarias, nuevo y pujante motor de crecimiento de Machala, a través de las plusvalías generadas por la revalorización del suelo. Como consecuencia, se habría acentuado un dualismo en el interior de la ciudad, entre unas áreas muy dinámicas, receptoras de estas grandes intervenciones y capaces de acoplarse a la globalización económica, y otros espacios que permanecen en una situación de marginalidad. Para comprobar esto, pasan a presentarse algunas de estas ideas agrupadas por grandes temas.

\section{IV.1. Los gobiernos populistas en Machala previos a la victoria del Partido Social Cristiano}

En Machala, como sucedía en Guayaquil, durante los años ochenta y noventa del siglo XX proliferaron los gobiernos populistas, en los que el nivel de corrupción era elevado. Como consecuencia, la ciudad carecía de una planificación urbana y de una dotación mínima de servicios en un momento en que se estaba consolidando el flujo migratorio desde otras regiones que se había iniciado unas décadas antes, y las tasas de crecimiento de la ciudad eran elevadas. Esta situación, lejos de ser atajada por los gobernantes locales, fue utilizada 
con fines electoralistas, constituyéndose negocios que organizaban las invasiones de terrenos, con permiso del gobierno local, que obtenía así un rédito de votos cautivos. Como señalan dos entrevistados:

«Existió un fenómeno de invasiones muy fuerte [...] en una semana tenías un barrio nuevo [...] durante muchos años sufrían carencia de luz, agua, alcantarillado [...] [se habían] hecho empresas que organizan las invasiones [...] que trabajaban con los mismos alcaldes [...] era una manera de obtener votos [...]. En Machala las invasiones crecieron mucho durante los años 80 [...] Mario Minuche [exalcalde de Machala] [...] formaba parte de esto [...] trabajaba con este tipo de cosas [...] tenía su gente que hacía esto [...] y había grupos de "invasores" a favor y en contra del alcalde».

«[En Machala] atravesamos por administraciones de carácter populista [...] que destrozaron la planificación, la participación ciudadana [...] entronizaron el latrocinio».

Este proceso se habría continuado en Machala un tiempo más, remitiendo en intensidad como consecuencia del progresivo descenso de la inmigración, pero a nivel de Ecuador habría seguido hasta la llegada de Rafael Correa al poder, quien pone freno a estos negocios de venta de terrenos, muy extendidos en Guayaquil. La consecuencia más inmediata de este fenómeno fue una extensión, similar al ocurrido a escala latinoamericana, de barriadas $-\mathrm{o}$ slums - de una sola planta y baja densidad, con muy pobres condiciones de habitabilidad, sin capacidad de solicitar la llegada de luz, agua potable o alcantarillado a la municipalidad y con amplios problemas sociales: delincuencia, analfabetismo, elevada mortandad infantil (Milbert, 2006). Junto con esta proliferación de los suburbios se da un abandono del centro urbano, existiendo una despreocupación por dotarlo de aceras, evitar las inundaciones en época de lluvias u ordenar el cableado eléctrico, situación que comienza a cambiar con la victoria del Partido Socialcristiano en 2005 (figura 1). Como señala uno de los entrevistados:

«La ciudad antes de esta administración [Partido Socialcristiano] tenía un gran déficit en servicios básicos e infraestructura vial [...] un 70-80\% del sistema vial era de tierra $[\ldots]$ en la actualidad más del $70 \%$ se encuentra regenerado».

\section{IV.2. La llegada de Carlos Falquez Batallas y la regeneración urbana de Machala}

La victoria de Carlos Falquez Batallas en las elecciones del año 2005 supuso la implementación de un proyecto de regeneración urbana que, como se dijo antes, se inspira del modelo de la ciudad de Guayaquil para llevar a cabo unas intervenciones que, en la línea de otras ciudades latinoamericanas, buscan mejorar el medio ambiente, la imagen y seguridad de áreas urbanas y promover la creación de nuevo habitacional, de espacios económicos renovados o de actividades de ocio (Nobre, 2002: 109). Este fenómeno, en Latinoamérica, es consecuencia del deterioro sufrido por las áreas centrales y la necesidad de una «reconquista simbólica» del centro por parte de la clase media (Janoschka, Sequera y Salinas, 2014), algo que ha señalado la propia municipalidad de Machala a través de una dialéctica que enfatiza 
la idea de «recuperación» de los espacios públicos (Municipalidad de Machala, s/f), lo que lo vincula a la idea de «reconquista del centro» en Guayaquil (Chiriboga, 2007: 200) a través de una concepción de recuperación y reorganización fragmentada de la ciudad (Janoschka, Sequera y Salinas, 2014: 1245) que obvia cualquier acción de planificación integral. Como enfatiza uno de los entrevistados:

«Aquí [en Machala] se aplica una regeneración urbana [...] que es una mala copia de lo que se hace en Europa [...] aquí no hay un Plan de Desarrollo [...] que lleva catorce años desfasado [...] falta una planificación integral».

Figura 2

DOS CALLES DE MACHALA ANTES (IZQUIERDA) Y DESPUÉS DE SU REGENERACIÓN URBANA (DERECHA)
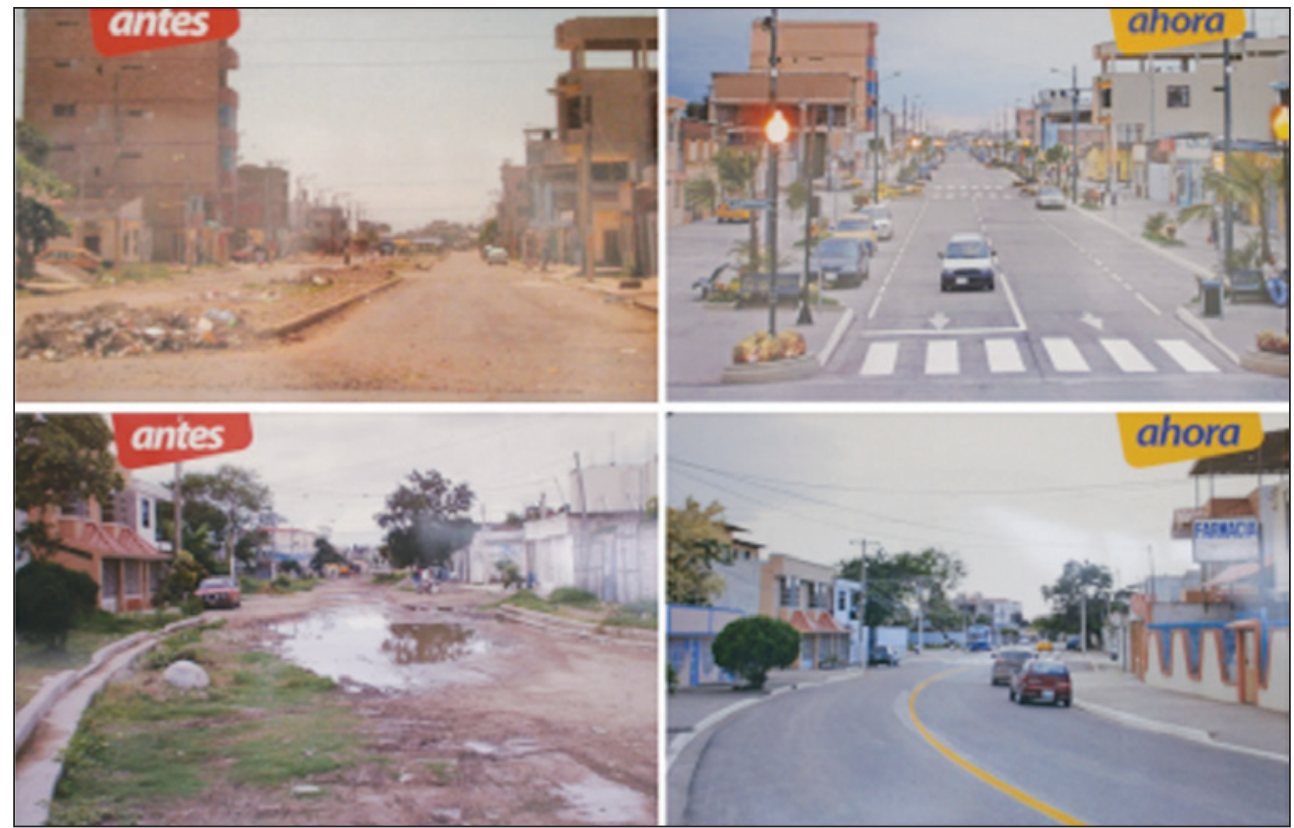

Fuente: Elaboración propia a partir de exposición pública en la plaza central de Machala.

Las ideas básicas de la forma que toma en Machala el proceso de regeneración urbana tienen que ver con la legalización de los terrenos invadidos décadas atrás, la dotación de servicios básicos a los mismos y la creación de espacios públicos (nuevos o regenerados) que incentiven la llegada de nuevos negocios y el fomento del ocio y el esparcimiento de la gente. Como señalan dos entrevistados:

«La regeneración urbana entraría con un proceso de legalización y reestructuración de los lotes de la planificación, a parte que se dota de servicios básicos e infraestructura vial, se dota de las líneas de fábrica [...] de los espacios que habían 
sido generados por procesos de invasión [...] se ha tratado de regularizar los sistemas viales y la tenencia de suelo [...] y crear los lineamientos para las zonas de esparcimiento [...] se han recuperado una serie de espacios públicos para el ocio de la población».

«La línea política de Falquez es atacar en la parte de regeneración urbana [...] antes de la regeneración Machala estaba desordenada [...] hay una parte de regeneración urbana que tiene que ver con el transporte [...] otra cuestión es la cablería de alta tensión [...] ahora buena parte de la ciudad tiene el cableado por debajo de la calzada $[. .$.$] es mucho más seguro [\ldots]$ ha mejorado el turismo $[\ldots]$ y la autoestima del ciudadano».

Un último elemento característico de la regeneración urbana de Machala es la existencia de fuertes paralelismos con el proceso iniciado en Guayaquil unos años antes, que sirvió de inspiración al alcalde socialcristiano de la ciudad para dar la misma «marca de identidad» a Machala que a la primera ciudad del país, reforzando la influencia cultural y política de Guayaquil que ya se comentó más arriba. En este sentido, una de las iniciativas de Carlos Falquez Batallas fue la creación de una muestra de arte, bautizada como «Salón de junio» a imagen y semejanza del «Salón de julio» que existía en Guayaquil desde hacía décadas. Esta influencia, desde el punto de vista arquitectónico, ha supuesto la consolidación de un urbanismo carente de identidad, postmoderno, en el que las intervenciones llevadas a cabo adolecen una falta de originalidad en la que, como señala David Harvey (2001: 358), se produce una repetición de patrones estandarizados, visible, como puede observarse en la figura 3 en las plazas, parques o avenidas regeneradas de una y otra ciudad. Aunque en la mayoría de las entrevistas se recogieron estas ideas, destaca la opinión de uno de los entrevistados que señalaba:

«Carlos Falquez [Batallas] es el hombre que empieza con esto [regeneración urbana] [...] es un fenómeno que se da por influencia de Guayaquil [...] se empezaron haciendo los proyectos muy idénticos a Guayaquil [...] es igual [...] los mismos materiales, el adoquinado, el porcelanato, falta un poco de personalidad, ser un poco más auténticos [...] tanto que se decía que somos "Machaquil" [...] es la misma tendencia [política] [...] y es el mismo grupo de derecha».

Estas cuestiones, más formales -aunque no exentas, como ha podido comprobarse, de un trasfondo ideológico visible también en otros procesos de regeneración urbana contemporáneos (Williams, 2014) - tienen su continuación en una serie de elementos como la temática de los espacios públicos regenerados, la securización de las áreas renovadas, la atracción de inversión externa hacia estas, la participación ciudadana en el proceso de regeneración urbana, o los intereses de las coaliciones o grupos de poder en este proceso. Por ello, a continuación, sin alejarse de la regeneración urbana en Machala, el artículo interpreta estos temas, siguiendo la metodología desarrollada en esta parte de la investigación.

Una primera cuestión aparece vinculada a la regeneración de plazas y parques, donde la municipalidad de Machala ha llevado a cabo una serie de intervenciones destinadas a crear espacios para el ocio y el disfrute de los ciudadanos, dado que existía una situación genera- 
lizada de abandono de estos lugares. Estas mejoras, además, han servido para la promoción turística de la ciudad, tanto de cara a los propios machaleños como para fomentar la llegada de visitantes de otros cantones. De hecho, si se consultan los atractivos turísticos de la ciudad en la web de la Municipalidad, puede comprobarse que todos los elementos visitables, con la excepción de la catedral de Machala y el puerto, son espacios públicos regenerados por la administración de Carlos Falquez Batallas. De esta manera, como señala Neil McInroy, las intervenciones en espacios públicos son utilizadas progresivamente para desarrollar imágenes positivas de un área, de manera que puedan servir para mejorar su atractivo hacia inversores potenciales y constituirse en un lugar que tanto residentes como visitantes pueden identificar con la ciudad (McInroy, 2000: 23-26).

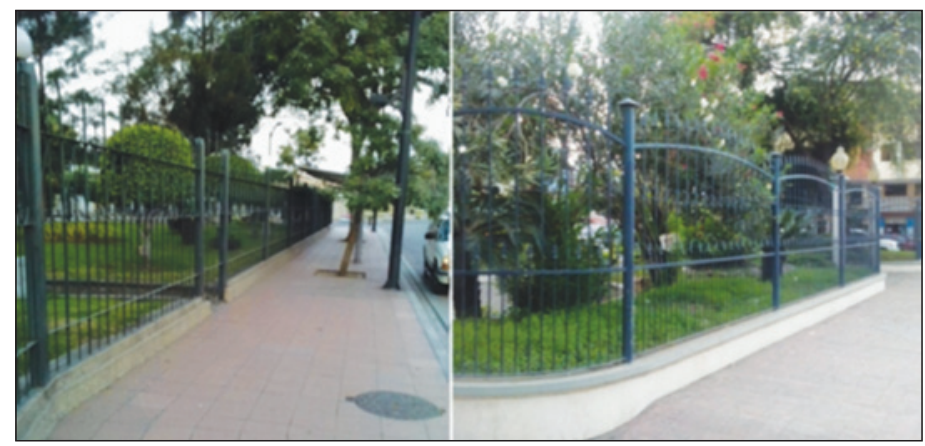

Fuente: Elaboración propia.

En el caso de Machala, el trabajo de campo llevado a cabo permitió identificar tres cuestiones ligadas a la regeneración de los parques y plazas. En primer lugar, una valoración generalmente positiva de las intervenciones, dado que estos eran espacios degradados en los que proliferaban los negocios ambulantes, mendigos, alcohólicos, etc. En segundo lugar, pese a esta necesidad de intervención, se ha encontrado, en general, una valoración crítica de los resultados de las mismas, por la forma (arquitectura, en general, postmoderna y descontextualizada de la historia de la ciudad), por el contenido (que a continuación se ejemplifica), y por el coste, que varios entrevistados consideraron muy elevados y en algunos medios se han calificado como «onerosos decorados» (Quirola, 2014). Y, en tercer lugar, se considera que muchas de estas intervenciones no han solventado uno de los problemas más acuciantes de la ciudad, la falta de áreas verdes. En referencia a la primera idea, uno de los entrevistados mostraba una idea, de un modo uotro compartida por casi todos los actores con los que se trabajó:

«La valoración de los parques [creo] que ha sido positiva [...] cualquier persona que haya conocido Machala ve que el cambio ha sido muy bueno [...] creo que ahora hace falta atacar otro tipo de cosas [...] lugares donde los servicios aún no llegan». 
Es decir, a pesar de la persistencia, como se verá a continuación, de importantes problemas, se ha considerado que la administración de Carlos Falquez Batallas ha supuesto el paso desde una política despreocupada por el desarrollo urbano hasta otra activa, pese a que ésta ha tenido un talante claramente empresarialista. En relación al contenido de las actuaciones en espacios públicos, el gobierno municipal ha impulsado una serie de intervenciones relacionadas con la historia de Machala, como la Plaza «Machala, amor y esperanza», dedicada a los creadores del himno de la ciudad, o el «Paseo Cultural Diego Minuche», en honor al primer alcalde electo democráticamente. Junto con estas, también se han desarrollado otras intervenciones, como el «Parque de Buenos Aires», el «Paseo de la Juventud» o el «Parque Lineal» (figura 4), dominadas por una arquitectura postmoderna, anónima y sin ninguna conexión con la tradición machaleña u orense, caracterizada por el uso de las maderas y las calles cubiertas.
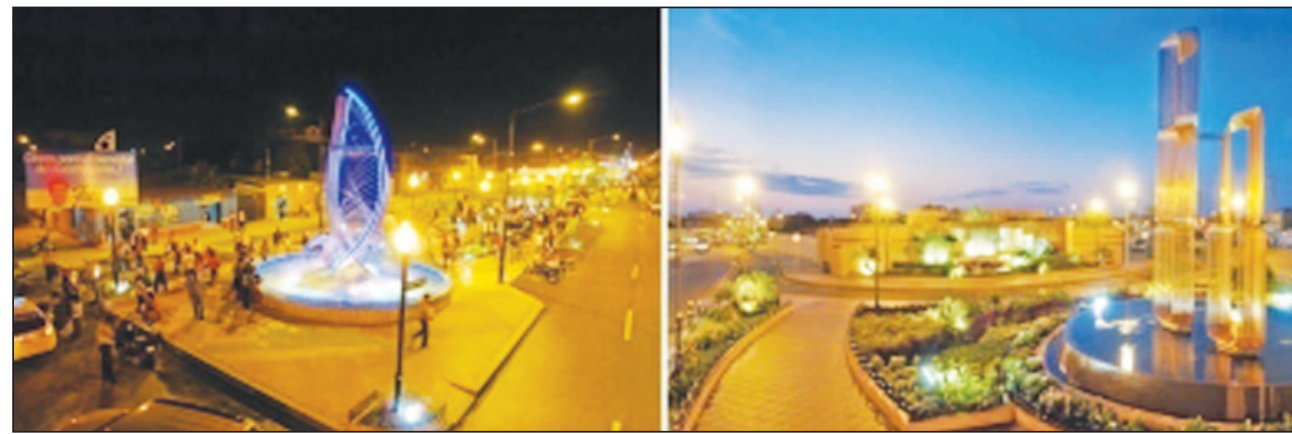

Fuente: http://www.machala.gob.ec

Sin embargo, las intervenciones más cuestionadas han sido aquellas que, junto a estas formas postmodernas, presentan unos contenidos completamente descontextualizados de la cultura de la ciudad, e incluso del país, como el «Parque de los Picapiedra» (figura 5), o que por su temática (un parque-monumento a Cristobal Colón) fueron causa de manifestaciones por parte de los ciudadanos de Machala, quienes derramaron pintura roja en la inauguración de esta plaza para protestar por la realización de un monumento a un hecho histórico que causó tantas muertes. El parque, formado por tres carabelas a las que se puede entrar para tomarse fotografías dentro, una gran brújula en el centro, formas arquitectónicas fragmentarias e, incluso, una fuente de agua con un arco bajo el cual se puede caminar (figura 5) es un ejemplo de lo que David Harvey denomina «escenografías» insertadas en contextos nuevos y sin ninguna relación con su entorno, que crean espacios asépticos y en los que se obvian los elementos trágicos o conflictivos de la historia en aras de crear áreas destinadas al ocio y el consumo, como es el caso de la Piazza d'Italia de Nueva Orleans que este autor desarrolla en su obra La condición de la Posmodernidad (Harvey, 1998: 115-118). Como señala uno de los entrevistados:

«En las intervenciones que se han realizado [...] yo me he quedado preocupado por la utilización de elementos que no tienen nada que ver con nuestra cultura [...] 
utilizaron un postmodernismo que es la destrucción de nuestra identidad urbana [...] en el tema del parque Colón [...] haciendo tributo a la llegada de Colón a América [...] con esas carabelas [...] ese tipo de situaciones se han dado [...] además con intervenciones muy costosas [...] ostentosas [...] además se celebra la colonialidad del poder [en este parque]».

Figura 5

PARQUE DE LOS PICAPIEDRA (IZQUIERDA) Y PARQUE COLÓN ANTES Y DESPUÉS DE SU REGENERACIÓN (DERECHA)

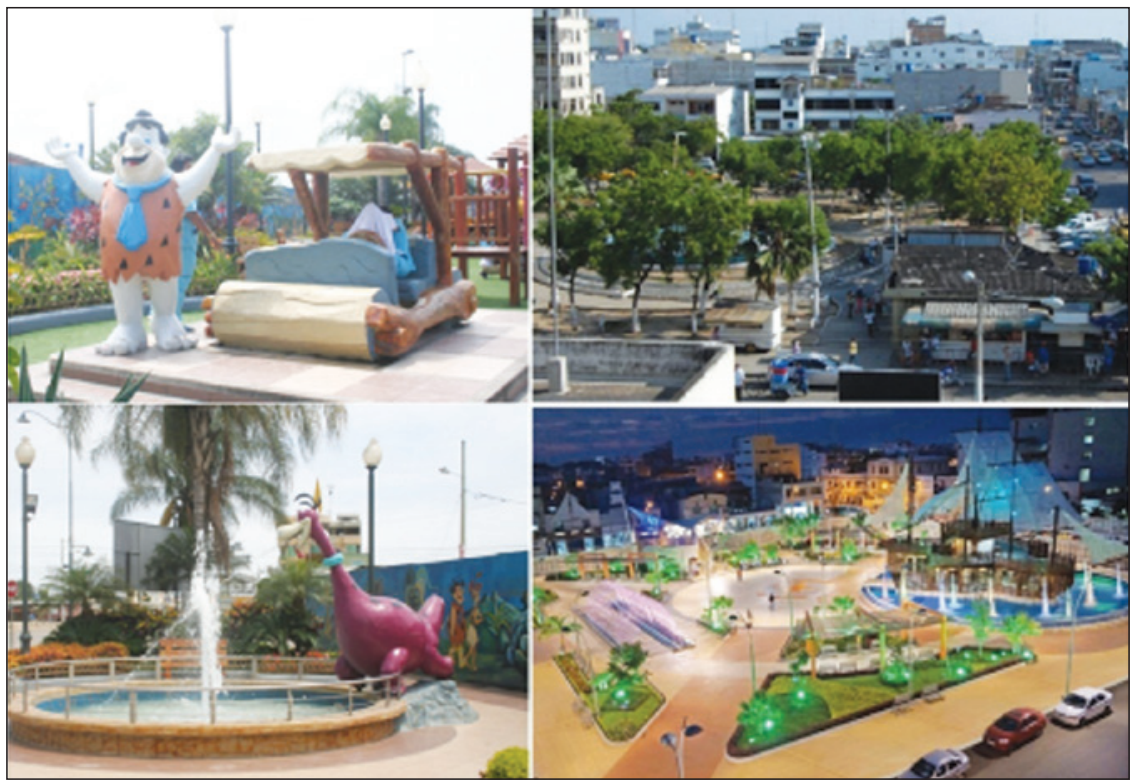

Fuente: José Manuel Castellano (Parque Picapiedra) y Diario La Hora (Parque Colón).

Finalmente, en relación a las áreas verdes de la ciudad, casi todos los entrevistados coincidieron en la carencia de estos espacios, algo que la prensa también ha destacado en ocasiones. De esta forma, Machala no cuenta con las suficientes áreas, tal como dice el Código Orgánico de Organización Territorial, Autonomía y Descentralización de Ecuador, dado que existen $0,5 \mathrm{~m}^{2}$ de área verde por cada habitante, cuando en realidad deberían existir $9 \mathrm{~m}^{2} \mathrm{de}$ áreas verdes por habitante, como lo establece la Organización Nacional de la Salud (El Telégrafo, 2014). Esto ha sucedido en paralelo a un proceso de «desarborización», como consecuencia de la regeneración urbana de la ciudad, ya que la ampliación de algunas avenidas y la renovación de determinados parques, como el parque Colón, supuso la tala de árboles que llevaban décadas en la ciudad (figura 5), lo que ocasionó incluso protestas sociales, desatendidas nuevamente por el consistorio local:

«No existe una dotación suficiente de áreas verdes [...] hubo muchas protestas de los jóvenes por la tala de áreas verdes en el centro de la ciudad». 
«Hay una falta de áreas verdes aún hoy en Machala [...] hay un proyecto de crear un gran área verde [...] en el antiguo aeropuerto [...] es necesario [...] no tenemos un área de parque específico que otras ciudades [sí] lo tienen».

Otro elemento, relacionado con el anterior, y puesto de relieve tanto en la propaganda que el gobierno municipal realiza de la regeneración urbana, como por los entrevistados, tiene que ver con el aumento de la vigilancia en estos espacios mediante el uso de la policía municipal y de compañías privadas de seguridad, a través de una política que en la regeneración urbana de Guayaquil se conoce como de «un guardia en cada esquina» (Chiriboga, 2007: 204). De esta manera, al igual que en otros espacios regenerados, en Machala se ha aplicado una doble batería de medidas destinada a hacer que éstos no sólo sean seguros, sino también que lo parezcan, mediante un aumento de la vigilancia por un lado, y la aplicación de códigos de conducta destinados a modificar hábitos considerados como «inapropiados» por el otro (Raco, 2003: 1870-1872). Algunos entrevistados han señalado la importancia de la seguridad y los avances logrados en las áreas regeneradas, principalmente a través del aumento de la presencia policial:

«Uno de los preceptos básicos de la regeneración es la delincuencia [...] si dejas que un espacio físico [sin atender] este tipo de gente [delincuentes] lo van a ganar [...] El parque Colón antes era un espacio a evitar [...] era muy inseguro [...] en Puerto Bolívar había espacios muy complejos [...] ahora son lugares de esparcimiento $[\ldots]$ ahora la idea ha sido ir recuperando estos espacios».

«En las zonas regeneradas se tiene la presencia de la policía municipal [...] sólo velan de una forma presencial [...] es una presencia [...] que controla, que educa [...] un carácter disuasorio» .

Un elemento esencial que ha aparecido en el trabajo de campo y que conecta con algunas problemáticas básicas de las regeneraciones urbanas es el de las intervenciones-fachada frente a la solución de las necesidades reales de la ciudad. Como señala Doucet (2007), se ha dado un giro en las preocupaciones políticas, pasándose de atender las necesidades relacionadas con la calidad de vida de los ciudadanos hasta la promoción de nuevos espacios para la inversión, a través de la regeneración urbana. De esta forma, se detraen fondos que podrían ser destinados a políticas de vivienda o educativas, contribuyéndose así a la polarización socioeconómica y a la creación de nuevas divisiones espaciales dentro de la ciudad.

En el caso de Machala esto es especialmente importante debido a su evolución histórica. Como se comentó antes, durante décadas la ciudad vivió una inmigración masiva que conformó grandes barriadas insalubres, con problemas de servicios y en áreas inundables; situación ante la cual los gobiernos locales poco o nada hicieron en un contexto de ausencia de una cultura de gestión urbana. En consecuencia, la ciudad viene sufriendo importantes carencias que han agravado sus problemas. Entre estas, destacan la inexistencia de un sistema de tratamiento de las aguas y de alcantarillado, de tal manera que la mayoría de las casas vierten sus desechos domésticos directamente a los esteros (pequeñas rías que conforman unos terrenos pantanosos sobre los que está asentada la ciudad) y ninguna calle cuenta con un sistema eficaz de filtración de aguas. Otro problema es la existencia de amplias barriadas, provenientes de las ya comentadas invasiones, a las que no llega una dotación adecuada de 
servicios básicos, configurando espacios de precariedad urbanística y social y que contrasta con las áreas regeneradas (figura 7). Finalmente, el tercer problema más grave que sufre la ciudad es la presencia en el centro de un mercado informal que invade varias calles y que constituye un foco infeccioso al distribuirse allá tanto ropa como carne, pescado o verduras. Estas problemáticas fueron señaladas por todos los entrevistados, destacándose especialmente la cuestión de las aguas servidas, y la existencia de una política, calcada de Guayaquil, que hace hincapié en las medidas «que se ven» (regeneración urbana) y no en aquellas más invisibles, como señalaba recientemente una publicación regional (Molina, 2014). Como indicaron varios de los entrevistados:

«En la actualidad [en Machala] hay el mismo lineamiento político [que en Guayaquil] [...] con las mismas ideas adaptadas a nuestro contexto [...] Guayaquil tiene los mismos problemas de fondo, llueve y se inunda, no llegan los servicios [...] es mucho más fácil hacer una regeneración urbana que atacar los problemas de las inundaciones [...] los políticos necesitan obras que se vean».

Se cambia una imagen urbana en el centro [...] pero se está obviando enfrentar los problemas de fondo de la ciudad [...] los servicios básicos ineficientes [...] falta de cobertura [...] más de 250.000 personas descargan directamente las aguas a los esteros».

«Yo creo que estaríamos en un 25\% [de viviendas sin acceso a servicios básicos] [...] el municipio tiene un problema de actualización de datos de su propio catastro [...] ni ellos tienen la película muy clara [sobre cuántas viviendas tienen estos problemas]».

«Tenemos un problema de mercado informal en el centro [...] zonas inundables [...] falta de asfaltado en muchas calles del centro».

«Tenemos una necesidad de 20.000-25.000 familias sin vivienda propia [en Machala] [...] la tierra no puede ser una mercancía, no puede ser revalorizada permanentemente».

Esta última idea enlaza con una cuestión que se encuentra en el fondo de casi todas las estrategias de regeneración urbana, incluida la de Machala: la búsqueda de inversiones externas que generen crecimiento en la ciudad. Como señala David Harvey, desde hace unas décadas resulta habitual la competencia entre ciudades, con las agencias encargadas de la regeneración urbana enfocadas en identificar y satisfacer las necesidades de potenciales inversores más que aquellas de la comunidad local (Harvey, 2000). En el caso de Machala, cabe distinguir dos áreas netamente diferenciadas pero sometidas a estos procesos. Por un lado, las calles regeneradas del centro urbano se han poblado de tiendas con pequeños negocios de ropa o tecnología, aprovechando la cercanía con Perú y los menores precios de este país, que han supuesto la apertura de estas tiendas por parte de familias (bananeros, camaroneros, empleados públicos) que tenían capital excedente para invertir, generalmente en sus hijas o esposas para que iniciaran estos negocios, enfocados a la demanda interna de bienes de consumo. Junto a este fenómeno, centrado en sectores muy concretos, en negocios familiares y con escaso valor agregado, por otro lado se ha dado una atracción de capitales transnacionales o, al menos, nacionales. Estos se han concentrado en la principal vía de Machala 
hacia el este, la 25 de junio, que constituye el lugar de entrada a la ciudad y donde hasta hace una década se ubicaban la Universidad provincial y un continuo de plantaciones de banano. Tras la regeneración de esta vía y la creación de una gran avenida de ocho carriles, han llegado tres superficies comerciales, dos de ellas pertenecientes a franquicias ecuatorianas, con supermercados, tiendas varias, entidades bancarias, zona de comidas y cines y se han generado nuevas urbanizaciones de lujo, de tipo gated community, rodeadas de un muro y con vigilancia privada las 24 horas y algunas franquicias internacionales como McDonald's (figura 6). De esta forma, se han creado espacios comerciales y residenciales no accesibles a todos los habitantes de la ciudad, generándose divisiones espaciales en el interior de la misma, como han señalado algunos entrevistados:

«Como todo proyecto [...] todo trabajo físico [la regeneración urbana] genera otras actividades al lado [...] la regeneración urbana genera más comercio [...] más actividades económicas».

«Carlos Falquez Batallas [...] su tendencia es la derecha, aplicando el neoliberalismo [...] era a favor de los centros comerciales, para él eso era sinónimo del progreso [...] parece una fiesta traer aquí [a Machala] a McDonald’s y ponerlo en la vía principal».

«Una de las promesas de Falquez [Batallas] fue hacer una red de mercados [...] pero no es favorable a la política que ellos llevan, que ha sido favorable a las grandes empresas transnacionales [...] y las grandes urbanizaciones de Machala [que se ubican al lado de los centros comerciales]».

«[Sería necesario avanzar] hacia un desarrollo urbanístico más estable, que no nos agolpe como nos agolparon las invasiones [...] más organizado, menos elitista [...] ahora [en] las urbanizaciones que he visto [...] la casa más barata cuesta $100.000 \$[. .$.$] una persona que gane el básico no va a poder comprarse la casa».$

Figura 6

VISTA DE LAAVENIDA 25 DE JUNIO EN MACHALA CON CENTRO COMERCIAL (IZQUIERDA-1), URBANIZACIÓN CERRADA (CENTRO-2) Y MCDONALD'S (DERECHA-3)

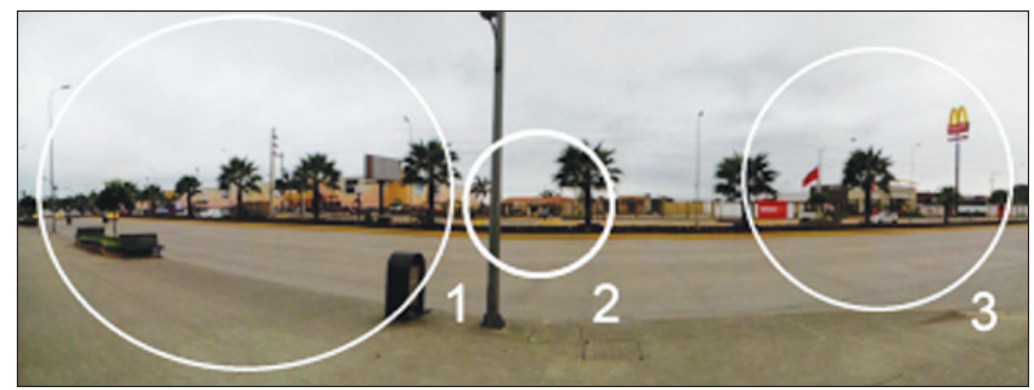

Fuente: Elaboración propia.

De esta forma, la regeneración urbana ha llevado a la creación de nuevos negocios y áreas de prestigio, con un fuerte incremento del valor de los bienes inmobiliarios. En este sentido, si 
la variación media del Índice de Precios al Consumo en Machala en 2013 fue del 3,68\%, en los valores de casas y departamentos fue del $5,82 \%$, más de dos puntos por encima del promedio de la ciudad y más de tres puntos sobre de la variación media del precio de la vivienda en Ecuador durante ese período, un 2,64\% (INEC, 2013), con lo que se estaría generando una acelerada revalorización de los bienes raíces en un contexto de afianzamiento de un modelo de consumo muy similar al de EE.UU. (centros comerciales, urbanizaciones cerradas, alto uso del factor suelo...) con la diferencia de que las capas de población que quedarían fuera de esta dinámica mantendrían unos estándares de vida propios de sociedades en vías de desarrollo.

Figura 7

REGENERACIÓN URBANA (IZQUIERDA) Y PERSISTENCIA DE ESPACIOS PRECARIO EN EL CENTRO Y LA PERIFERIA (DERECHA)
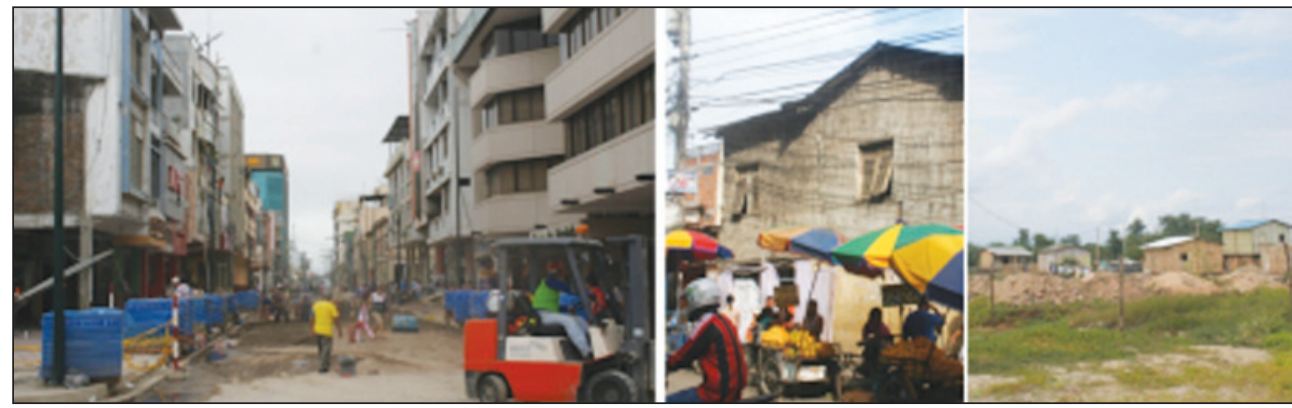

Fuente: José Manuel Castellano (2013).

Una última consecuencia de este proceso de regeneración urbana, muy conectada a la idea anterior, tendría que ver con la participación ciudadana y las coaliciones de poder, o growth machines que Molotoch señala en su texto clásico de la década de los setenta. Como argumenta este autor, las ciudades estarían dominadas por unas élites políticas y económicas, cuyo deseo es favorecer el crecimiento de las mismas, medible en la expansión del área urbana, lo que genera grandes beneficios a los propietarios de la tierra y otros grupos de interés (Molotoch, 1976: 310-311). En el caso de Machala, pueden encontrarse dos ideas fundamentales: la existencia de unos grupos de poder representados por la burguesía agraria, que concentra las tierras y el capital, que tiene una clase política a su imagen y semejanza, y que ejerce un férreo control sobre los medios de comunicación (Astudillo, 2012: 59); y la ausencia de participación real ciudadana, que quedaría supeditada a las decisiones de dichas élites. Como puede verse en los siguientes comentarios, existiría una legislación ad hoc a los intereses de estos grupos sociales, quienes tendrían, tal y como señalaba Molotoch, deseo de obtener una revalorización del suelo del que son propietarios y una participación interesada en la regeneración urbana, a través de empresas constructoras o proveedoras de materiales, con muy poca originalidad, al estar claramente inspirados en aquellos de Guayaquil (figura 3):

«Los grupos dominantes que llegan al poder [...] empiezan a hacer administración a su manera [...] habiendo ordenanzas [...] estas no sirven [...] hacen tabla rasa y empiezan a manejar a la ciudad a sus conveniencias, a sus intereses de grupo». 
«Por supuesto [que habría un interés de los grupos oligárquicos de Machala en la regeneración urbana], ¿quién cree que está ganando con ello? [Estos grupos] tienen empresas que son los mayores beneficiarios [...] La regeneración urbana se ha concentrado desde el centro hacia el este [...] las tres o cuatro familias que tienen tierras están hacia el este [...] tienen una revalorización extraordinaria de la tierra [...] la utilización del adoquín, del mobiliario, todo es copia de Guayaquil».

El control sobre los medios de comunicación que se comentaba más arriba se ejercería por parte de estos grupos de poder, presentes en el accionariado de los cuatro periódicos provinciales, quienes han aplaudido todas las iniciativas de regeneración urbana ${ }^{1}$. Esto habría servido, a decir de los entrevistados, tanto para crear un clima favorable a las intervenciones de la municipalidad, como para no dar voz a otros problemas ya comentados (falta de servicios, inseguridad, infravivienda, etc.) de tal manera que al quitar estos problemas de la escena local se habría desincentivado también el asociativismo y la participación ciudadana, reducida a su mínima expresión según varios entrevistados y un fiel reflejo de lo que se apuntaba en el apartado teórico. En este sentido, como señalan tres actores respecto a los medios de comunicación y la asociatividad local:

«Los medios de comunicación son propiedad de las personas que han dominado la política [...] aplauden las intervenciones urbanísticas [...] se busca el apoyo unánime y los temas que no interesan, no se tratan.[...] Esto de la asociatividad desde el mismo poder se ha desincentivado [...] porque interesa fomentar la individualidad».

«Tenemos las herramientas necesarias [para la participación ciudadana] pero a veces por lineamientos políticos esto no se hace [...] ahora todo proyecto necesita la carta de haber sido socializado [...] a veces no lo hacemos [...] lo hacemos por cumplir [...] y el propio ciudadano no se empodera de esa oportunidad que tiene de ser partícipe directo de la toma de decisiones».

«Debería darse mayor nivel de participación de los ciudadanos para que justamente no sólo empujen en los proyectos [...] sino para propiciar mejores condiciones de vida [...] Machala está muy bonita, cuidadita, faroles, pero está muy descuidada en las cuestiones de fondo [...] ha habido acciones de protesta pero de gente que no tiene mayor peso».

\section{CONCLUSIONES}

Como ha podido comprobarse a lo largo de este artículo, el modelo de regeneración urbana de Machala copia, no sólo en lo estético sino también en lo político, lo cultural y lo ideológico, los preceptos básicos del desarrollado en Guayaquil. Mientras que en la principal

1 Simplemente a modo de ejemplo: La Hora, 05/03/2012, «Avanza regeneración de la Circunvalación Norte». Disponible en: http://www.lahora.com.ec Consulta: 21/07/2014. Correo, 22/01/2014, «Municipalidad de Machala inaugura regeneración urbana de barrio Brisas del Mar». Disponible en: http://www.diariocorreo.com.ec/ Consulta: 21/07/2014. Diario Opinión, 29/09/2013, «Regeneración urbana contribuye al crecimiento del turismo en Machala». Disponible en: http://www.diariopinion.com/ Consulta: 21/07/2014. 
ciudad de Ecuador, el eje de la regeneración urbana es el Malecón 2000, donde se dan las lógicas de estandarización estética y control social, en Machala estas lógicas se circunscriben a los parques y plazas regeneradas (Picapiedra, Colón, etc.), al eje de la calle 25 de junio, que concentra urbanizaciones cerradas, centros comerciales y franquicias, $y$, en un futuro, al proyecto de renovación del malecón de Puerto Bolívar. El progresivo agotamiento del crecimiento económico en torno al modelo agro-exportador y su sustitución por el negocio inmobiliario seguiría beneficiando a las coaliciones de poder de la ciudad, a partir de la formación de una burbuja inmobiliaria como consecuencia de la sustitución de un modelo que no gestionaba la ciudad por otro que lo hace desde una perspectiva empresarialista. Dicho modelo estaría promoviendo unas «islas de inversión» en Machala que coexisten con grandes bolsas de pobreza en los suburbios de la ciudad cuyas necesidades básicas se desatienden.

Desde un punto de vista político, este modelo de gestión empresarial habría servido al gobierno local para crear, al igual que en Guayaquil una «imagen de marca» que le ha beneficiado en su consolidación en el poder, primero durante las dos legislaturas de Carlos Falquez Batallas (2005-2009 y 2009-2014) y después en el gobierno actual de su hijo, Carlos Falquez Aguilar (2014-2019). Esta imagen, verdaderamente personalista, se habría traducido en una aparición constante de la alcaldía y de su cabeza principal, en la cartelería y el mobiliario que acompaña al proceso de regeneración urbana, pasando por la propia maquinaria encargada de llevar a cabo la regeneración (figura 8). De esta manera, transformación urbana y gestión política pasarían a estar imbricadas en la historia de la ciudad, quedando plasmada para la posteridad la labor del alcalde.

Figura 8

UTILIZACIÓN POLIITICA DE LA REGENERACIÓN URBANA

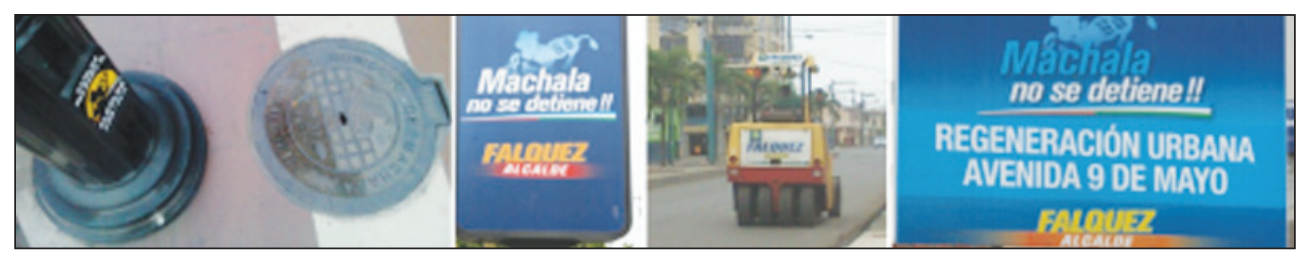

Fuente: Elaboración propia.

La regeneración urbana de Machala es un proceso en el que no sólo la participación ciudadana está ausente, en parte como consecuencia de la propia debilidad de las organizaciones sociales en Ecuador. También está ausente la atención de los intereses de la ciudadanía, con su reflejo en unos índices de pobreza más altos que los de las otras ciudades del país o en un estancamiento de Machala en su índice de Gini, lo que otorga otras perspectivas desde las cuales cuestionar la eficacia del modelo de gestión empresarial más allá del fomento de los espacios vigilados, de las privatizaciones o de las operaciones de limpieza social que, como se ha visto, son destacadas por la bibliografía internacional.

Este artículo, a partir del estudio del proceso de regeneración urbana de Machala, muestra que, pese a haber pasado ya algunas décadas desde su momento de auge, buena parte de los postulados de la geografía crítica siguen vigentes hoy día, visibles en los procesos de regeneración urbana de muchas ciudades latinoamericanas. Estos postulados, 
sin embargo, deben combinarse hoy con elementos locales y trayectorias concretas para poder ser interpretados con mayor exactitud. En el caso de Machala, esto supone aceptar la existencia de una dependencia cultural, económica y política de Guayaquil, que se ha mantenido a lo largo de las décadas y que ha influido sobre las decisiones de los grupos de poder locales, explicándose así la forma que toman los modelos de desarrollo urbano. Sería interesante continuar estos trabajos a partir del estudio de otras ciudades de tamaño intermedio de Ecuador o de otros países de la región. De este modo, sería posible comprobar si existe una difusión generalizada de estos patrones de gobernanza urbana, con la consiguiente copia de modelos de otras metrópolis regionales o, si por el contrario, se darían también modelos alternativos que, al igual que sucedió con Curitiba, Brasil, planteen otras formas, más inclusivas y participativas, de gestionar la ciudad. Tanto esto, como la puesta en práctica de planes de gestión de la regeneración urbana para llevar a cabo actuaciones apoyadas en estudios sobre la ciudad, podrían ser dos interesantes líneas de futuro desde los espacios de la academia y la gestión urbana.

\section{BIBLIOGRAFÍA}

ALLÁN, H. P. (2011): «Regeneración urbana y exclusión social en la ciudad de Guayaquil: el caso de la Playita de El Guasmo» en Pobreza urbana en América Latina y el Caribe (Di Virgilio, M. M., coord.). Buenos Aries, Edit. Clacso, 69-105.

ANDRADE, X. (2007): “"More City,” Less Citizenship: Urban Renovation and the Annihilation of Public Space» en Urban Regeneration and Revitalization in the Americas: Toward a Stable State (Carrión, F. y Hanley, L. M., eds.). Washington, D.C., Woodrow Wilson International Center for Scholars, 107-143.

ASTUDILLO, C. (2012): Liderazgos políticos en la Provincia de El Oro. Machala, Universidad Técnica de Machala.

BARRANTÍA, R. (1991): Crecimiento Urbano de Machala. Machala, Departamento de Investigaciones Socioeconómicas de la Universidad Técnica de Machala.

BOISIER, S. (2006): «América Latina en un medio siglo (1950/2000): el desarrollo, ¿donde estuvo?». Investigaciones Regionales, $\mathrm{n}^{\circ}$ 9, 145-167.

CARLEY, M. (2000): «Urban Partnerships, Governance and the Regeneration of Britain's Cities». International Planning Studies, $\mathrm{n}^{\circ} 5$ (3), 273-297.

CARRIÓN, F. (1996): «Realidad urbana del Ecuador y crisis de las ciudades» en La Ciudad que Queremos, Experiencias de participación barrial (VV.AA.). Quito, Ed. ACJ., 13-26

CARRIÓN, F. (1998): «Gobierno local y nuevos liderazgos: La hora de los alcaldes» en Decentralización territorial y su impacto en la gestión local (VV.AA.). Cali, ESAP, 77-84.

CHIRIBOGA, H.(2007): «Regeneración urbana:privatización del espacio público, políticas de seguridady tematización en diario El Universo de Guayaquil». Diálogos, revista académica de la Federación Latinoamericana de Facultades de Comunicación Social, ${ }^{\circ}$ 75, 199-209.

CUENYA, B. y CORRAL, M. (2011): «Empresarialismo, economía del suelo y grandes proyectos urbanos: el modelo de Puerto Madero en Buenos Aires». EURE, n 37 (111), $25-45$. 
DE MATTOS, C. (2010): Globalización y metamorfosis urbana en América Latina.Quito, Ed. Olacchi y Municipio Metropolitano de Quito.

DELYSER, D., y SUI, D. (2014): «Crossing the qualitative-quantitative chasm III: Enduring methods, open geography, participatory research, and the fourth paradigm».Progress in Human Geography, n 38 (2), 294-307.

DOUCET, B. (2007): «Flagship regeneration: panacea or urban problem?». Paperpresented at the EURA Conference: The Vital City, 12-14 September, Glasgow. Disponible en: http://www.briandoucet.com/publications.html. Consulta: 18/07/2014.

EL TELÉGRAFO (2014): «Machala apenas cuenta con 3,5 kilómetros de ciclovías», en El Telégrafo, 02/03/2014. Disponible en: http:/www.telegrafo.com.ec/regionales/regional-sur/ item/machala-apenas-cuenta-con-35-kilometros-de-ciclovias htmlConsulta: 04/08/2014.

EURE (2009): «Presentación. Competitividad urbana: alcances y desafíos». EURE, $\mathrm{n}^{\circ} 35$ (106), 5-7.

FERNÁNDEZ-SATTO, V., y VIGIL-GRECO, J. I. (2007): «Clusters y desarrollo territorial. Revisión teórica y desafíos metodológicos para América Latina».Economía, Sociedad y Territorio, $\mathrm{n}^{\circ} 6$ (24), 859-912.

GARCÉS, C. (2004): «Exclusión constitutiva: las organizaciones pantalla y lo anti-social en la renovación urbanade Guayaquil». Iconos, $\mathrm{n}^{\circ}$ 20, 53-63.

GAVENTA, J., y VALDERRAMA, C., (1999): Participation, Citizenship and Local Governance. Background note prepared for workshop on Strengthening participation in local governance.Institute of Development Studies, 21-2 junio. Disponible en: http://www. participatorymethods.org/resource/participation-citizenship-and-local-governance.

HARVEY, D. (1998): La condición de la Posmodernidad. Buenos Aires, Amorrortu Editores. HARVEY, D. (2000): Spaces of Hope. Edimburgo, Edinburgh University Press.

HARVEY, D. (2001): «From managerialism to entrepreneurialism: the transformation of urban governance in late capitalism» en Spaces of Capital. Towards a critical geography (Harvey, D.). Londres, Routledge y Chapman \& Hall, 345-368.

HEALEY, P., et al. (1992): Rebuilding the city. Property-led urban regeneration. Londres, Spon Press.

INEC (2013): Serie Histórica de Variaciones Mensuales Nacional y por Ciudades de Enero a Diciembre-2013. Quito, Instituto Nacional de Estadística y Censo. Disponible en: http://www.ecuadorencifras.gob.ec/indice-de-precios-al-comunidor-2013/. Consulta: $18 / 07 / 2014$.

INEC (2014): Encuesta Nacional de Empleo, Desempleo y Subempleo - ENEMDU. Indicadores de Pobreza y Desigualdad. Marzo de 2014. Quito, Instituto Nacional de Estadística y Censo.Disponible en: http://www.ecuadorencifras.gob.ec/documentos/web-inec/ POBREZA/2014/marzo-2014/140415\%20PobrezaMarzo.pdf. Consulta: 12/07/2014.

INEC (2014b): Encuesta Nacional de Empleo, Desempleo y Subempleo - ENEMDU.Evolución de Mercado Laboral. Junio de 2014.Instituto Nacional de Estadística y Censo. Disponible en: http://www.ecuadorencifras.gob.ec/empleo-encuesta-nacional-de-empleodesempleo-y-subempleo-enemdu/. Consulta: 30/07/2014.

JANOSCHKA, M.; SEQUERA, J. y SALINAS, L. (2014): «Gentrification in Spain and Latin America - a Critical Dialogue». International Journal of Urban and Regional Research, $\mathrm{n}^{\circ} 38$ (4), 1234-1265. 
KANAI, M. y ORTEGA-ALCÁZAR, I. (2009): «The Prospects for Progressive CultureLed Urban Regeneration in Latin America: Cases from Mexico City and Buenos Aires». International Journal of Urban and Regional Research, $\mathrm{n}^{\circ} 33$ (2), 483-501.

KEESE, J., y FREIRE, M. (2006): «Decentralisation and NGO-municipal government collaboration in Ecuador». Development in Practice, $\mathrm{n}^{\circ} 16$ (2), 114-127.

KORTHALS, W. (2002): «Local Government and the Decentralisation of Urban Regeneration Policies in The Netherlands». Urban Studies, n 39 (8), 1439-1452.

LÓPEZ-MORALES, E. J. (2010): «Real Estate Market, State-Entrepreneurialism and Urban Policy in the 'Gentrification by Ground Rent Dispossession' of Santiago de Chile». Journal of Latin American Geography, $\mathrm{n}^{\circ} 9$ (1), 145-173.

MAINWARING, S., y SCULLY, T. R. (2008): «Latin America: Eight Lessons for Governance». Journal of Democracy, $\mathrm{n}^{\circ} 19$ (3), 113-127.

MCINROY, N. (2000): «Urban Regeneration and Public Space: The Story of an Urban Park». Space and Polity $\mathrm{n}^{\circ} 4$ (1), 23-40.

MILBERT, I. (2006): «Slums, Slum Dwellers and Multilevel Governance». The European Journal of Development Research, $\mathrm{n}^{\circ} 18$ (2), 299-318.

MOLINA, R. (2014): «Los retos del nuevo alcalde de Machala». Primera Plana, nº 79, julioagosto 2014, 8-10.

MOLOTCH, H. (1976): «The City as a Growth Machine: Toward a Political Economy of Place». American Journal of Sociology, nº 82 (2), 309-332.

MUNICIPALIDAD DE MACHALA (s/f): «Alcalde Falquez firmó contrato para construcción de parque en El Retiro». En http://www.machala.gob.ec/content/noticias.html. Consulta: 16/07/2014.

MURILlO, R. (2009): Machala: Proceso de identidad. Machala, Universidad Técnica de Machala.

NARVÁEZ, R., y VINUESA, W. (2003): «Una ciudad media del Ecuador: Machala. Propuesta dignositiva», en IX Encuentro de Geografía de América Latina. México. Disponible en: http://observatoriogeograficoamericalatina.org.mx/egal9.html. Consulta: 19/08/2014.

NICKSON, A. (2011): «Where Is Local Government Going in Latin America? A Comparative Perspective», Working Paper No. 6. Visby: International Centre for Local Democracy, 1-36. Disponible en:

http://www.icld.se/pdf/icld_wp6_printerfriendly.pdf.Consulta: 16/09/2014.

NOBRE, E. (2002): «Urban regeneration experiences in Brazil: Historical preservation, tourism development and gentrification in Salvador da Bahia». Urban Design International $\mathrm{n}^{\circ} 7,109-124$.

ONU Hábitat (2014): Construcción de ciudades más equitativas: políticas públicas para la inclusión en América Latina. Colombia, ONU Hábitat.

PORTAIS, M., y LEÓN, J.(1987): El Espacio Urbano en el Ecuador, Red Urbana, Región y Crecimiento; Geografía Básica del Ecuador Tomo II Geografía Urbana. Quito, Instituto Panamericano de Geografía e Historia.

QUIROLA, F. (2014): «Deuda Municipal». Diario Opinión, 03/06/2014, 11. Disponible en: http://www.diariopinion.com/comentario/verArticulo.php?id=887855. Consulta: $17 / 07 / 2014$. 
RACO, M. (2003): «Remaking Place and Securitising Space: Urban Regeneration and the Strategies, Tactics andPractices of Policing in the UK». Urban Studies, $\mathrm{n}^{\circ} 40$ (9), 18691887.

RAMÍREZ, F. (2009): Entre el poder y la crítica. Movimientos sociales, sociedad civil y democracia en el Ecuador. Buenos Aires, Consejo Latinoamericano de Ciencias Sociales.

ROBERT, L. (2009): Empresarios ecuatorianos del Banano. Quito, Codeu. Corporación para el Desarrollo.

RODRÍGUEZ, A.; MOULAERT, F. y SWYNGEDOW, E. (2001): «Nuevas políticas urbanas para la revitalización de las ciudades en Europa». Ciudad y Territorio, Estudios territoriales, $\mathrm{n}^{\circ} 33$ (129), 409-424.

SAAD-FILHO, A. (2005): «The Political Economy of Neoliberalism in Latin America» en Neoliberalism. A Critical Reader (Saad-Filho, A., y Johnston, D., eds.). Londres, Pluto Press, 113-120.

SCARLATO, M. (2013): «Social Enterprise, Capabilities and Development Paradigms: Lessons from Ecuador». The Journal of Development Studies, n 49 (9), 1270-1283.

SOMOZA, J. (2013): «Gobernanza urbana, competitividad y procesos de renovación en las ciudades medias españolas». Boletín de la Asociación de Geógrafos Españoles, ${ }^{\circ}$ 61, 47-66.

TELLA, G. y POTOCKO, A. (2013): «La calle comercial en ciudades intermedias: Iniciativa, gestión y participación en clave de desarrollo». Revista Digital Plataforma Urbana. Disponible en: http://www.plataformaurbana.cl/archive/2013/01/03/la-calle-comercialen-ciudades-intermedias-iniciativa-gestion-y-participacion-en-clave-de-desarrollo. Consulta: 22/07/2014.

VILAGRASA, J. (1999): «Las ciudades pequeñas y medias en España»,en La ciudad. Tamaño y crecimiento. Actas del III Coloquio de Geografía Urbana (Domínguez, R., coord.). Málaga, Universidad de Málaga y AGE, 17-50.

WILLIAMS, J. (2014): «Bogotá, urbanismo posmoderno y la transformación de la ciudad contemporánea». Revista de Geografía Norte Grande, $\mathrm{n}^{\circ}$ 57, 9-31.

WONG, D. (2005): «Regeneración urbana: privatización del espacio público, políticas de seguridad y tematización en diario El Universo de Guayaquil». Ciudades, n 9, 179-191.

YEUNG, H. (2003): «Practicing New Economic Geographies: A Methodological Examination». Annals of the Association of American Geographers, $n^{\circ} 93$ (2), 442-462. 
